\title{
ANÉCDOTAS LITERARIAS DEL SIGLO XVI
}

JoSÉ FRADEJAS LEBRERO

Catedrático Emérito

El ms. 18.220 de la Biblioteca Nacional de Madrid tiene dieciséis folios (de $31,5 \times 22$, cuya caja es de $27 \times 15,4$ ), repartidos en dos cuademillos de cuatro y doce hojas, respectivamente. La última está en blanco.

Está encuadernado - mejor diríamos desencuadernado- en pergamino, cuya portada tiene un índice de Relaciones de varios sucesos (todos ellos del siglo XVI) que continúa en la contraportada con media docena más, pero que no tienen ningún contacto con el contenido.

Me atrevo a atribuir una fecha anterior a 1550 por las siguientes razones: refiriéndose a la Emperatriz, dice:

La Infanta doña Ysabel de Portugal que después fue Emperatriz y Reina de Castilla, TRAÝA este mote: O César o nada.

De la utilización del Imperfecto de Indicativo creo que se deduce claramente que Doña Isabel ya no vivía, por tanto es posterior a 1539; y, refiriéndose al secretario Cobos (fol. 5), dice: TRAE, en Presente, luego aún vivía y, habiendo muerto en 1547, el ms. debió escribirse entre 1539 y 1547.

Lleva por título el primer folio, con tinta roja: MOTES AGUDOS, que ocupan los folios 1-7.

Algunos de estos motes proceden de poemas del siglo Xv; estos son del poeta Cartagena:

Con merecello se paga (fol. 2).

Esfuerçe Dios el sufrir (fol. 2) ${ }^{1}$.

' Dutton, B.: Cancionero del S. XV, Salamanca, Universidad, 1990, T.I, pp. 219 b y 221. 
No todo son motes, hay algún epitafio: del Duque Valentino, hijo del Papa Alexandre (fol. $4 v$ ), que repiten Fray Antonio de Guevara, Julián del Castillo en la Historia de los Reyes Godos, las Crónicas del Gran Capitán (NBAE, T.X, p. 345), y en el siglo XVII, Ambrosio de Salazar. Hay también intercalados algunos poemitas de D. Rodrigo Ponce, Duque de Arcos y don Fadrique Enríquez, Almirante de Castilla.

A partir del folio $7 \mathrm{v}$ y hasta el $15 \mathrm{v}$ son cuentecillos: entre ellos se hallan unas anécdotas atribuidas a famosos escritores de los siglos xv y xvi: Diego de San Pedro (7v), Pero Mexía (7v), Garci Sánchez de Badajoz (8-9v) y Hernando del Pulgar (1lv y 12).

\section{Diego de SAn Pedro}

De Diego de San Pedro, poeta, autor de una excelente Pasión de Cristo, y novelista político? con la Cárcel de amor, a la vez sentimental, el llorado Keith Whinnom, tras estudiarlo meticulosamente en ¿Diego de San Pedro converso?, llega a esta conclusión:

No es imposible que el autor Diego de San Pedro fuese converso y tal vez tengan razón Márquez y Bataillon al percibir en su obra actitudes y preocupaciones típicas de los neocristianos $^{2}$.

Algo semejante se me ocurrió decir a mí en mi conferencia sobre Hernando de Pulgar:

No me persuado (a pesar del estudio del benemérito Cantera Burgos) de que Pulgar fuera converso.

Es cierto, como dice Whinnom, que Luis Zapata incluye otras tres anécdotas diferentes, pero no lo es menos que estas que ahora publicamos son medio siglo anteriores $\mathrm{e}$ inciden en el mismo aspecto. He aquí todas cinco:

I. Un cauallero cas6 con una judía rica siendo muy enemigo de los que tocauan en este linaje. Encontró con Diego de San Pedro con quien él solía passar muchos chistes y motes y como le vio venir dízele:

- Por Dios, señor, que un tal como vos andaua yo agora a buscar.

Respondió Diego de San Pedro:

-Pues cómo, señor, ¿estáis caballero en la burra y andaisla a buscar? (fol. 7v).

II. Descendían muchos por una escalera, y acaso fue el postre Diego de San Pedro. Dixo uno de los que desçendían:

- Jurara yo a Dios que el del cabo auía de ser marrano.

Respondió Diego de San Pedro:

—Andá, señor, que no ay cabo sin heuilla (fol. $7 \mathrm{v}$ ).

III. Al que trobó la Pasión dixeron, y no sin causa, que lo avía dicho tan bien como testigo de vista.

\footnotetext{
2 San Pedro, Diego de: Obras completas, ed. K. Whinnom, Madrid, 1973, Clás. Castalia, T.I, p. 1721.
} 
IV. Este prometió a otro de su jaez que haría cierta cosa, y añidió que le daua su fe y palabra dello. Tardáuase en cumplir la promesa, y dixo el otro:

- Señor, hazedlo, pues me distes vuestra fe de hazello.

- Señor — dixo aquel一, yo no puedo agora, y si os dí mi fe fue para remendar la vuestra.

Estaua allí otro hombre honrado, y por tenerlos en paz dixo:

-Bien está, señores, que como sois ambos de un paño no se parecerá el remiendo.

V. Dizen que entre los mismos enbió a tratar el uno commo el otro por carta de darle su hija en casamiento, y él le respondió:

- Señor compadre, en merçed os tengo la oferta, mas de judío harto tenemos acá, avnque no tan ruin como lo vuestro3.

\section{GARCI SÁNChez de BADAJOZ}

Julia Castillo es autora de una excelente edición del poeta Sánchez de Badajoz, pero en relación con las anécdotas deja bastante que desear. Rechaza las anécdotas XIII y XIV de Gallagher ${ }^{4}$, que no se refieren propiamente a Garci Sánchez ... y aclara:

Nosotros aquí hemos reproducido nueve de entre las conocidas y publicados dos inéditas que anotara el poeta Juan de Arguijo, IV y V de nuestro Cancionero (p. 31n).

Enumeramos las publicadas por Castillo, ampliando sus notas y las que de ella figuran en nuestro manuscrito.

1. Garci Sánchez ... subió al terrado (terraza) y dice estar en terrado.

Ms XI; Santa Cruz, M. de: Floresta española, ed. Cuartero y Chevalier, VI, III, 2, p. 421, Barcelona, Crítica, 1997; Timoneda, J. y Aragonés, J.: Buen Aviso y Portacuentos .... ed. Cuartero y Chevalier, Cuento 2, pp. 316-317, Madrid, Espasa-Calpe, 1989, Col. Clásicos Castellanos; Pinedo, L.: Liber facetiarum, fol. 42.

2. Hace malas coplas porque «no ando enamorado».

Francisco de Portugal: Arte de Galantería, Lisboa, 1670, p. 71.

3. I caer del caballo la dama dice: Los ojos ... y él responde: señora y el corazón / vuestros son.

Aragonés, núm. 12, p. 325.

4. Fía la barba a la condesa de Palma, pero no el oficio.

Ms. IV; Arguijo, J.: Cuentos, ed. Chenot y Chevalier, Sevilla, 1979, núm. 34.

5. No bastaba hacer la Pasión, sino firmarla.

Arguijo, núm. 41.

6. Juego de palabras entre cuento (millón) y yerro (error) y elección entre dos novios.

Timoneda, J.: Buen Aviso ..., núm. 158 (65), p. 303; Zapata, II, 268; Covarrubias, G.: Tesoro (1611), p. 352a, Fuentes, Alonso de: Miscelánea, n. ${ }^{\circ} 157$.

\footnotetext{
${ }^{3}$ Zapata, Luis: Miscelánea (Varia Historia), ed. M. Terrón Albarrán, Badajoz, Pedro de Valencia, 1983, T.I, facsímil de ms. 2790. Son los números III, IV y V.

${ }^{4}$ Gallagher. P.: The Life and Works of G.S. de Bad ajoz, London, Támesis, 1968.
} 
7. Hace 30 años te sigo necio y no me sufrías un hora loco. Ms I; Pinedo: ... BAE, T. 176, p. $111 \mathrm{a}$.

8. «A Garci Sánchez pedía».

Lope de Vega: Quien ama no haga fieros, N. Ac., T.XIII, Acto I, pp. 405a.

9. La calentura de su hermano, asno, va lenta.

Zapata, Luis: Miscelánea, ed. fac. Terrón, fol. 361v.

10. Al morir, su hábito de S. Francisco y Santiago, le dirá a Dios que murió en Invierno. Melo, F. ${ }^{\circ}$ M. de: Hospital das letras, Lisboa, 1652, p. 371.

11. Garci Sánchez, el corregidor Xerez y la vihuela.

Santa Cruz: VI, III, p. 421; Román, Fray C.: Repúblicas del mundo, 1595, p. 304.

Castillo se congratula por la recopilación de estas once anécdotas y me resulta muy extraña su afirmación:

He reproducido las anécdotas que de Garci Sánchez se conservan casi en su totalidad.

Destaco las cuatro últimas palabras para luego comentarlas; porque la extensa nómina de manuscritos e impresos utilizados en su edición, parece avalar esta afirmación, pero me pregunto: ¿los leyó todos? Porque, a propósito de los números 1 y 11 , cita a Melchor de Santa Cruz (ed. de 1598), pero da la casualidad que existen otras cinco anécdotas más que invalida el sentido de las palabras que he destacado:

12. Todos meriendan a pie, y el moro Zaide a caballo.

Santa Cruz: III, II, 4, p. 389.

13. A Garci Sánchez pedía:

Santa Cruz: III, IV, 5, p. 391.

14. Pedís todavía por Dios.

Santa Cruz: III, V, 10.

15. Quitar se me fizo una cabeza, pero más difícil dos.

Santa Cruz: VI, III, 6, p. 421; Pedro del Mercado: Diálogos de filosofía natural y moral, 1558, fol. 151; Lope: Angélica en Catay, III, BAE, T. 234, pp. 354b-355a.

16. V.m. es la gala, y ese caballero es la china.

Santa Cruz: VIII, II, 3, po. 448.

Me he detenido en este aspecto porque en el número 11 incluye también al padre Fray Jerónimo Román: Repúblicas del mundo (1595), que reproduce Menéndez Pelayo, de donde nuestra editora quizá tomara la anécdota, pero se le pasó a don Marcelino - y, por ende, a ella- - esta otra curiosa cita del P. J. Román:

Garci Sánchez de Badajoz, hombre noble en estos reynos y muy enamorado, por hauer traydo las cosas sagradas para sus amores, le priuó Dios del juicio y murió sin el (1575, R30906-1), L. II, Cap. VI, fol. 54c. 
Pues bien, hoy traemos otras dieciocho anécdotas (digo mal, son catorce, porque cuatro las utiliza también Castillo y otras dos son poemas incluidos en su edición) inéditas y desconocidas; quizá no sean las únicas que de Garci Sánchez nos quedan y algún día aparezcan más:

I. Garçi Sánchez de Badajoz besó las manos al Emperador en Écija, y viéndole assí, mal traydo, dixo el Emperador a su hermano, el jurado Orellana, que por qué le traýa tan roto y descosido.

Respondió su hermano que era un perdido; que quanto le dauan hazía pedaços, que no avía quien le sufriesse.

Respondió Garçi Sánchez:

- ¿Qué le pareçe a V. Majestad que le [h]e sufrido a éste treinta años de neçio y no me quiere él a mi sufrir uno de loco?

Castillo: núm. VII, con variantes, p. 29; Pinedo, L. de: Liher facetiaum, BAE, T. 176, p. 11 lb; Timoneda, J.: Buen aviso ..., pp. 287-88; Zapata, L. de: Varia historia (Miscelánea), ed. Montiel, Madrid, Castilla, 1949, T.II, $\$ 195$, p. 266 (con variantes). Aparece también en Alonso de Fuentes, Miscelánea, $\mathrm{n}^{\circ} 161$ y en el número 111 atribuido a fray Ínigo de Mendoza.

II. El mismo Garçi Sánchez siendo visitado de la Condessa de Palma dezíale que por qué se dexaua creçer la barua. Respondió él:

- Crezca pues creçen mis penas.

Dixo la Condessa:

-Pues estas uñas, ¿para qué son tan largas?

Respondió él:

-Déxelas V.S., que son mis cuchillos.

Importunóle la Condessa que se hiciese la barba; y demandó unas tiseras.

Él rehusaua mucho y le dezía que en ninguna manera lo haría.

Dixo la Condessa, pues ¿cómo, no fiaréis de mi vuestra barua?

Respondió él:

- La barba sí, más no el ofiçio.

III. Estauan el mismo Garçi Sánchez y otro cauallero al pie del púlpito y descendía fray Íñigo de Mendoza de predicar y preguntóles:

-Pues ¿en qué se va entendiendo?

Dixo Garçi Sánchez:

- Vamos en gran confusión que sois Dios en el sermón y el diablo en desçindiendo. Aquí está el señor don Juan, que él se çisca y yo me çisco, que no casarán Françisca con San Françisco.

\section{Donayre}

IV. Andaua el mismo Garçi Sánchez unas estaçiones y díxole una dama que castigase a su hermano.

Preguntada por qué le dixo que le rezasse un Aue María.

Respondió: Señora, no mereçe pena porque lo [h]a por El ventris tui.

Aparece también en Alonso de Fuentes: Miscelánea, $n .^{\circ} 161$ y en el $n .^{\circ} 111$ atribuido a Pray Iñigo de Mendoza.

V. Yendo a uer su amor Garçi Sánchez que estaua loco, díxole:

一Señor Garçi Sánchez ¿cómo estáis?

Yél:

-Qual me dexastes. 


\section{Metháphora}

VI. Un Corregidor de Écija fue a ver a Garçi Sánchez y hallóle tañendo una vihuela y él rogóle mucho al Corregidor la tomasse. El Corregidor no quería. Díxole él: hecho.

-Tómela v.m. si quiera porque vea yo en poder de Justicia a quien tanto mal me [h]a

Castillo: núm. XI, pp. 30-31.

VII. Una dama hermosa fue a ver a Garçi Sánchez y preguntóle el que venía con ella qué le pareçía de ésta dama. Dixo él:

-Esta no es dama.

Dixo el otro:

-Pues, ¿qué es?

Dixo él:

- Serafín de mi vida vella.

VIII. Sacó uno un sayo de damasco blanco con unos fuegos de carmesí (pelo) y era confesso, preguntándole a Garçi Sánchez qué le pareçía de aquellos fuegos. Respondió que bien sino que estauan sobre casa pajiza o, bien si la casa no fuera pajiza.

\section{Metháphora y pica}

IX. Estauan dos pajes en el palaçio del Príncipe don Juan porfiando qual auía de entrar delante. Y el uno de ellos era hidalgo, y el otro confesso. Viéndolos assí en esta porfía, Garçi Sánchez trauó del confesso y dixo:

- Sábado, dexa passar al Domingo.

Puede verse también en el Licenciado Vidriera de Cervantes.

\section{Pica}

$X$. Fue a uer a Garçi Sánchez un mercader rico y a pocas palabras que habló con él le conoció Garçi Sánchez. Vínole acaso, estando assí sentados la hora en que se suele ençerrar en una cámara a passar su passión, y leuantándose dixo:

-Señor, quedaos a Dios, que me voy al Padre.

Dixo el mercader:

-Pues, señor, encomendadnos lo allá.

Respondió él:

-Dezirme ía Dios, traeisnos encomiendas de los que no nos conoçen.

XI. Salióse a tomar ayre Garçi Sánchez en un terrado, y estando assí solo salió una dama su vezina y díxole que qué hazía a tal hora en aquel lugar. Respondió él:

- ¿Dónde puede mejor estar el muerto que en terrado?

Castillo: I, p. 27.

XII. La Condessa de Palma fue a ver a Garçi Sánchez y sentóse encima de la cama, que estaua acostado. Dezíale Garçi Sánchez que se sentase mejor. Dezía la Condessa que era la cama angosta y no cabría. Respondióle êl:

-Pues en la angosta cama y largo camino se conoçe el buen amigo. 
XIII. Fue Luis de Guzmán una vez a ver a Garci Sánchez y rogándole que dixessen alguna cosa con la vihuela, dixo Garçi Sánchez:

- Todo lo que dixere ha de ser sobre mí.

Y dixo Garçi Sánchez:

$$
\begin{aligned}
& \text { Garçía, uno de los } \\
& \text { que biuen vida contenta, } \\
& \text { en poco cargo sois vos } \\
& \text { al día sancto en que Dios } \\
& \text { os [h]a de tomar la cuenta; } \\
& \text { que al tiempo del relatar } \\
& \text { la sentençia leda y triste } \\
& \text { podéis vos muy bien hablar } \\
& \text { que cuenta te puedo dar } \\
& \text { de aquello que no me diste. }
\end{aligned}
$$

XIV. El mismo Garçi Sánchez viendo una mora muy hermosa llamada Haxa dixo assí:

Como quando el sol assoma

por una montaña baxa

que con pura fuerça doma

nuestra vista y la relaxa,

tal es vuestro rostro Haxa,

cruda lança de Mahoma

que las entrañas raxa,

como la piedra balaxa

Castillo: Poema ..., núm. 14, p. 83.

que no la come carcoma.

XV. El mismo Garçi Sánchez hizo de si una comparaçión a la culebra, la qual suele estar muy viçiosa y [h]a de estar assí:

$$
\begin{aligned}
& \text { Aquella que por do va } \\
& \text { haze surcos con el pecho } \\
& \text { por las piedras donde da } \\
& \text { tiene tiempo o ha } \\
& \text { de sus heridas provecho } \\
& \text { pero yo que de tu mano } \\
& \text { soy herido, tal me hallo } \\
& \text { que ni tarde ni temprano } \\
& \text { nunca espero verme sano } \\
& \text { ni es posible deseallo. }
\end{aligned}
$$

Castillo: Poema,, núm. 13, p. 82.

\section{Donaire}

XVI. Yvan dos caualleros a ver a Garçi Sánchez, y encontraron a la puerta con su hermano a quien ellos no conoçían. Él les respondió que le perdonasen que no estaua, para ver que estaua ocupado en çierta passión. Dixo el uno de ellos como vio que aquella era escusa vana:

-Vámonos, señor, que este deue ser por quien dixo el dicho [secretas pasiones mías].

Cfr. Arguijo, núm. 669.

\footnotetext{
s Encima, tachado: bien hecho.
} 
XVII. Estauan don Íñigo Manrique y Garçi Sánchez en Málaga. Dixo don Iñigo que hiziessen una copla sobre su partida. Porfiaron ambos sobre el començar, y en fin començó don Ínigo y dixo:

Ve do vas mi pensamiento enbidia tengo de ti.

Acabó la cançión Garçi Sánchez y dixo:

y verás el bien que ví,

sin sentir el mal que siento.

Cfr.: Castillo, núm. 39, pp. 124-125.

XVIII. A Garci-Sánchez pedía un sacristán que le hallese una invención que sacase su manga de cruz un día; pero viéndole el calzón roto, $y$ en pedir prolijo, «Saca unas calzas, le dijo, y será buena invención».

Lope de Vega, Quien ama no haga fieros. N. Ac. XIII, A. I., p. 405, que repiten Palacio y Rivera en 1864:

Había en una ciudad antiguamente la costumbre de que el día del Corpus se hiciese un regalo al sacristán que sacase una más rara invención en la procesión que, como todos sabemos se celebra en aquella solemnidad.

Entre los sacristanes que tenían que aspirar al premio, había uno que iba siempre muy remendado, y que con especialidad llevaba unas calzas tradicionalmente rotas y malparadas.

Este sacristán fue casualmente el que se llegó a un tal Garci-Sánchez, hombre de peso, con el fin de preguntarle qué sería lo que él podría sacar que llamase mayormente la atención de las gentes. Garci-Sánchez, sin titubear, le respondio:

-Unas calzas.

\section{NOTA FINAL}

A propósito del poema núm. 8 (p. 77), afirma Castillo: «se trata de la composición final del Cancionero de Gallardo». Es una afirmación rotunda y sui generis, porque el Cancionero tiene, en la edición de Azáceta, ochenta y ocho poemas y éste, al que nos referimos, lleva el número ochenta y seis; es, pues, el antepenúltimo.

Por cierto, Azáceta afirma que es inédito; tengo que disentir de tan buen y antiguo amigo, porque está publicado desde 1859 (Gayangos), nuevamente en 1935 (Horsman, G.C.) y 1949 (Montiel); es decir, en todas las ediciones la Varia Historia (Miscelánea), de Luis Zapata de Chaves: cap. 9, fol. 10, del ms. 2790 (T.I, \& 9, p. 70, ed. Montiel).

Mi amiga escogida en çiento

y el çiento en mill escogidas

y el mill escogido en quento

y el quento entre las nacidas.

Es el hiperbólico resumen de la leyenda romana de Sulpicia, hija de Patérculo y esposa de Fulvio Flaco, elegida por los decenviros como la más casta de las romanas, acreedora a guardar la Venus Verticordia. 
PLINIO, C.: Historia natural, Libro VII, Cap. XXXV.

VAlerio MÁximo: Los nueve libros de los ejemplos, trad. Diego López, Madrid, V.M. VIII, 15 últimos, Imprenta del Reino, 1647, Libro VIII, Cap. XV, ejemplo último.

LunA, D. Álvaro de: Libro de las claras e virtuosas mugeres, Ed. Castillo, Toledo, 1908, Libro II, XXXIII, Sulpicia, fija de Patróculo, p. 148a.

P. Baltasar de Vitoria: II Parte de los Dioses de la gentilidad, Madrid, Ariztia, 1738, Libro VI, Cap. II, p. 359.

\section{Pero MeXía}

Casi todas las anécdotas, que no pican en lo satírico, son rasgos de ingenio de los escritores: una veces con reminiscencias literarias, otras con observaciones juiciosas.

Sobre Pero Mexía tenemos pocos recuerdos de su ingenio, que son frecuentísimos en sus obras (Silva de varia lección y Colloquios); yo recuerdo de mi época estudiantil aquella costumbre de abrigarse el cráneo que dio origen al mote de siete bonetes y que luego encontré en Rodrigo Caro.

Sabido es que era astrólogo e hizo algunos buenos pronósticos, hasta el de «su mesma muerte, 20 años antes», dice Francisco Pacheco.

I. Había adivinado Pero Mexía, por la posición de los astros de su nacimiento, que había de morir de un sereno [frialdad nocturna], y andaba siempre abrigado con uno o dos bonetes en la cabeza debajo de la gorra que entonces se usaba, por lo cual le llamaban siete bonetes, sed non auguriis potuit depellere pestem; porque estando una noche en su aposento, sucedió a deshora un ruido grande en una casa vecina, y saliendo sin prevención al sereno, se le ocasionó la muerte, siendo de no muy madura edad .

Pacheco afirma: sobrevinole una grave enfermedad de la cabeza que le duró todo el tiempo que vivió.

II. Estauan en conversación algunos caualleros y uno, un escribano, a meter su cucharada, y a lo que pareçía venía borracho.

Estando un poco callados preguntó uno a Pero Mexía que qué le pareçía de ellos.

Respondió que estauan en mortuorio, y el escribano, que estaua sentado en un costal de trigo, pareçía la ofrenda.

III. Estando comiendo muchos caballeros, y entre ellos un doctor marrano, traxeron un pernil de toçino çercado de romero, dixo Pero Mexía a ello:

-Doctor que en figura viene de romero no le conozca Galuán?.

IV. Estaua, un enano, en la plaça, del Duque de Medina en Sevilla, sacándose al sol aradores. Passó Pero Mexía y díxele:

- Una cosa veo en vos contra natura, allende de otras, y es que el arador suele estar en la sarna y agora la sarna está en el arador ${ }^{8}$.

"Menéndez Pelayo, M.: Orígenes de la novela, Santander, Aldus, 1943, Tomo III, pp. 49-50.

7 Alvar, M.: El romancero viejo y tradicional, México, Porrúa, 1971, Romance núm. 98, p. 88.

${ }^{*}$ Fuentes, A.: Miscelánea, n. ${ }^{\circ} 9$. 
De las dos anécdotas existentes en este manuscrito, la primera incide en el mundo judeo-converso: se disculpa Mexía de que el pernil del cerdo que han asado con romero viene disfrazado (algo así como el ajo y el perejil que cuentan de Isabel la Católica cuando afirmó que aquel, «el villano», venía vestido de verde) ${ }^{9}$.

\section{Hernando del Pulgar}

Tres anécdotas aparecen de Hernando; dos eran inéditas cuando las dí a conocer en una conferencia sobre él en 2004 y tienen la misma faceta judaica que las referidas de Diego de San Pedro. Helas aquí:

\section{El historiador no el soldado}

I. Hernando del Pulgar y otro cauallero motejáuanse. El Pulgar al otro de puto y el otro a él de confesso. Vio un día a este cauallero en una mula y la silla muy trasera y díxole:

- Sr. al Carillo, siempre caualgáis trasero.

Respondió el otro:

-Señor, hágalo por no matarle en la cruz.

Esta anécdota la repite, como anónima y más explícita, el Galateo español:

Pero aún más en hondo entran estos dichos satíricos quando tocan en el linage y en la honra, como hizo un cristiano nuevo a otro por motexalle de buxarrón, que como le viesse ir cavallero en un rocín, muy al cavo, le dixo:

-Compañero, ¿por qué subís tan a las ancas?

A lo qual le respondió:

-Si subo tan atras es por no matalle en la cruz.

(Gracián Dantisco, Lucas: Galateo español (1573), ed. M. Morreale, Madrid, CSIC, 1968, Clásicos Hispánicos, Cap. XI, pp. 148, 36-42) y también en Pinedo, Liber facetiarum, n. ${ }^{\circ}$ 7, fol. 27 :

Un caballero ýbase paseando en las ancas de una mula con otro, y preguntado por qué caualgaua tan trasero (motejándole de bujarrón), respondió motejando de judío.

II. Estaua éste mismo a la puerta de un herrador y llegó Pulgar y dixo:

- Hermano, mostráme acá tres clauos para este que le chapea la chrisma.

Respondió Pulgar:

-Por Dios, que pensé que los seríades para la manta: «Esto es por que en Córdoua las mugeres públicas se publican con una manta». (fol. 11v).

III. Ymportunaua mucho la Reina doña Isabel a Pulgar que dondequiera que en la Historia mentasse al Rey, que hiziesse también memoria de ella; y como él lo rehusasse muchas vezes por usar de la fidelidad del buen chronista, una vez mandándole la Reina, que lleyesse cierta parte de la Chrónica, llego a un capítulo que dezía, en tal día a tantos de tal mes parieron los reyes nuestros señores. La Reina reprehendiendo [h]auerlos en aquel caso puesto juntos, respondió que Su Alteza se lo [h] auía mandado assí y que no se podía reuocar, y hasta el Arzobispo de Toledo hablo, y aun porfí en ello: no lo quiso quitar (fol. 12).

${ }^{9}$ Santa Cruz, M.: Floresta española, (1574), Parte II, Cap. I, núm. 11. El intríngulis está en el villano, afirmaba Galeno y le sigue el Arcipreste de Talavera (P.I, Cap. XVI), que «el ajo e el vino atriaca es de los villanos», y aunque a doña Isabel no le gustaba. Fernando $V$ decía «buena especia es el ajo». 
Quizá simultáneamente, se encuentra en el Floreto:

La Reyna doña Ysabel mandaua a Hernando del Pulgar que le leyesse la historia o chrónica que escriuia y mandáuale que donde en un hecho o dicho mentasse al Rey, que la juntasse también a ella que se hallaua en ello. Él, por guardar la fidelidad de buen coronista no lo hazía sino quando passaua assí que la Reina se hallaua en alguna cosa; con todo esto le importunó que no hiziesse otra cosa. Passó assí que auiendo la Reyna parido, y escriuiendo en día y hora, dixo:

- En tantos de tal mes y tal año parieron los Reyes nuestros señores.

- La Reyna, marauillada de auerlos puesto en tal caso juntos, mandávale que lo quitase, y él no lo quería hazer, pues que su Alteza se lo avía mandado tantas vezes; en fin, el Arzobispo de Toledo acabó con él que lo enmendasse.

Floreto de anécdotas y noticias (S. XVI), ed. de F. J. Sánchez Cantón, Madrid, 1948, Memorial Histórico Español, T. XLVIII, p. 34. Se repiten en el s. XIX: Boira, R.: Cuentos, 1862, T. III, 259; Palacio, M. y Rivera, L.: Museo cómico, 1863, T. II, p. 152.

Y lo repite Arguijo abreviadísimo:

Culpó la Reina Católica a Hernando del Pulgar, su cronista, que refiriendo en su historia cierta acción del Rey Católico, su marido, no la puso en nombre de ambos como se le había ordenado. Parió poco después la Reina a doña Juana, y escribió Hernando del Pulgar:

-En tal día, a tal hora, parieron los Reyes una hija ...

Arguijo, Juan: Cuentos, ed. Chenot y Chevalier, Sevilla, 1979, p. 40, núm. 29.

Se repiten en el s. XIX: Boira, R.: Cuentos, 1862, T. III, 259; Palacio, M. y Rivera, L.: Museo cómico, 1863, T. II, p. 152.

IV. Dezía Hernando del Pulgar: quanto esta vida más crece, más decrece, y quanto más anda más va a no andar.

Fuentes, A.: Miscelánea, $n^{\circ}{ }^{129}$. Otra vez mas asparece el carácter moralista.

\section{NOTA FINAL}

Aunque esta no se refiere al aspecto tratado, es interesante porque demuestra la familiaridad entre Sancho de Rojas y el Rey Católico.

La primera anécdota nos plantea un problema que quisiéramos aclarar. Pulgar y $\mathrm{Ca}$ rillo - hombre de donaire que también menciona El Cortesano, de Castiglione- se motejan: Pulgar a Carrillo de puto y Carrillo a Pulgar de judío.

Dejando aparte el modo de motejar que expresa por extenso Castiglione, quiero relacionarlo en primer lugar con Fray Pedro de Covarrubias que, en su Remedio de jugadores, afirma:

A este linage de jugar se reduze el gracioso dezir, el donoso hablar los donayres, bien corregido motejar sin offensa de Dios sin injuria y afrenta del próximo sin deshonestas palabras: del qual juego solos los muy discretos saben jugar porque ellos solos se saben gozar. Leemos de sanctíssimos varones como Sant Juan euangelista con sus discípulos y Sant Antón con los suyos auer usado destos honestos passatiempos y donayres ${ }^{10}$.

16 Fray Pedro de Covarrubias: Remedio de jugadores, Burgos, Alonso de Melgar, 1519, P.1, Cap. VI, fol. XIIIv, R-31474. 
Pero con mayor precisión quiero referirme a la tacha de judío. En una breve biografía de Pulgar - expuesta en una conferencia- dudé de la afirmación casi categórica que se hace generalmente, refiriéndose a Pulgar como judío.

No dudo que don Francisco Cantera tuviera razón en cuanto a su origen u abolorio último, pero sí dudo y mucho en cuanto al sentido religioso que ello implica. Que se imbrican ambos aspectos no hay duda, y por eso quiero traer a cuento unas anécdotas reales de don Fernando el Católico. Nunca más necesarias y patentes por cuanto significan en el aspecto religioso y real.

En el Liber facetiarum de Ludovico Pinedo et amicorum, ms. de la BN de Madrid núm. 6960 , fol. $54 \mathrm{v}$, figuran las tres anécdotas siguientes ${ }^{11}$ :

I. Sancho de Rojas al Rey Católico.

Dixo Sancho de Rojas al Rey Católico una noche que aportó a su casa en Cabia. Después de hauerle dado muy bien de cenar, y el Rey pidió adrede una cosa que no era posible hauerse para comer.

[Respondió Sancho de Rojas]

- ¿Cómo, estáis en casa agena y pedís gullorías? (fol. $54 \mathrm{v}$ ).

Las verdaderamente interesantes son las dos siguientes, donde afloran los aspectos judaicos:

II. El mesmo Sancho de Rojas dixo al rey católico (estándole cortando un bestido de monte) supplico a Vuestra Alteza que si sobrare algo de esse paño me haga merced de ello. El rey le dixo que de buena gana.

Otro día dixo el Sancho de Rojas al rey:

-Señor, pues sobró algo?

Dixo el rey:

- No por vuestra vida, ni un tanto (y señalóle una $O$, hecha con la mano en el pecho, la qual solían traer los judíos de señal, de paño en el pecho puesta)

[Le dijo Sancho de Rojas] (tachado)

- Hablóme aquel morico en algarabía, como aquel que bien lo sabe. (fol. 54v).

III. El mesmo Sancho de Rojas andando a caça con el Rey lançaron un halcón a una garza, y atravesando una paloma, fue a ella y dexó la garça.

El rey enojado del halcón dixo a Sancho de Rojas:

- ¿Qué os parece?

Respondió:

-No sé que diga que aun hasta aquí no nos quiere dexar esta paloma.

Porque el Sancho de Rojas y el rey eran primos hermanos, hijos de dos hermanas (fol. 54v).

Queda claro por una parte la tacha de judío de la primera, no así la de la segunda que, sin embargo, se aclara con esta otra versión del Memorial de algunos casos (28) que publicó el Sr. Sanz Arizmendi en la Revue Hispanique (1917), T. 40, pp. 228-255.

Hagamos constar dos aspectos:

1. Que Sancho de Rojas pasa a llamarse MARTíN de Rojas, quizá por efecto de la transmisión oral, porque al parecer es más moderna, segunda mitad del siglo XVI, y

"Fueron recogidas por Paz y Melia en sus Salas españolas, BAE, T. 176², p. 106 a y b. 
2. Fue, ya utilizada, despreciando u olvidando las anteriores, por don Américo Castro en su "Español», palabra extranjera: razones y motivos, Madrid, Taurus, 1970, Cuadernos de Taurus núm. 89, pp. 42-43.

El Rey D. Alonso Onceno huvo en Doña Leonor de Guzmán un hijo llamado D. Fadrique Henrríquez, el qual en Doña Paloma, judia de Guadalcanal, huvo a D. Alonso Henrríquez, primer Almirante de su casa.

Este D. Alonso huvo en Doña Juana de Mendoza, con quien casó (mas por fuerça que por voluntad) tres hijos y nueve hijas, a todas las quales casó con grandes señores de Castilla, y el hijo mayor D. Fadrique casó cinco, y la una fue madre del Rey Don Fernando el quinto. De manera que en Castilla, casi no hay señor que no descienda de D.. Paloma.

Supuesto esto, sucedió que andando el dicho Rey D. Fernando a caça, fue un halcón con una garça, y alexóse tanto, que el Rey la dexó passando adelante y siguiendo Martín de Roxas, hasta que le vio dexar la garça y tirar tras una paloma. En esso se bolvió donde estaba el Rey. El Rey que le vido, preguntóle por su halcón. Martín de Roxas dixo: «Señor, allá va tras nuestra agüela». Que este Martín era también descendiente de la misma Paloma.

Se aclaran así un tantico las alusiones judaicas y familiares ora entre parientes, amigos y conmilitones. Tanto más cuanto en este último texto se afirma

casi no hay señor que no descienda de $\mathrm{D} .{ }^{\mathrm{a}}$ Paloma

lo que nos da pie para intentar una justificación contra el judaísmo que se atribuye a unos u otros, según el concepto que tomemos.

Don Fernando - y la mayor parte de los señores de Castilla - era descendiente de raza judía; los que creemos en la teoría trireligiosa y trirracial de don A. Castro (cristianos, moros y judíos), recibimos de este hecho una ayuda importante. Pero cuando la transportamos al aspecto religioso, aquí negamos la mayor.

Judíos hubo que, como Mosén Diego de Valera, demostrado por José Simón Díaz en 1945, se les supuso posteriormente —casi como adivinación- judíos en virtud de no sé qué tendencias religiosas, como incluso se le han atribuido a otros poetas y personajes que no renegaron de su raza y tuvieron un sentido acrisoladísimo de su fe cristiana. No sé, pues, por qué Fernando de Rojas o Hernando de Pulgar fueron menos cristianos en sentido religioso y, sin embargo, ¿actuaron en sentido étnico nacional diferente?

$\mathrm{Ni}$ lo veo claro ni estimo un pimiento del criptojudaismo no religioso de estos personajes, pese al caso del abuelo de Santa Teresa quien, «cuando me place hágame cristiano, cuando me place hágame de origen racial judío». 